\title{
Razão, história e justificação da lei civil segundo Thomas Hobbes
}

\section{Wladimir Barreto Lisboa*}

Sumário: 1. Sobre a lei natural e a lei civil; 2. A crítica à tradição e ao modelo jurídico do common law enquanto fundamento da lei civil; 2.1. A crítica à razão artificial; 3 . O que o século XVII tem a nos ensinar. Referências Bibliográficas.

Resumo: $\mathrm{O}$ autor procura analisar a relação existente entre lei natural e lei civil em Thomas Hobbes. Para isso analisa sua crítica à história e ao common law enquanto incapazes de fundar a racionalidade do poder civil. Mostra-se igualmente de que modo o poder soberano encontra seu fundamento nas leis morais. Por fim, indica-se como a igualdade de direitos, tal como pensada na modernidade, sobretudo em Hobbes, parece inviabilizar a idéia de direitos cujos titulares seriam grupos e não indivíduos.

Palavras-chave: Thomas Hobbes; Ética; Política; Lei natural; Lei civil.
Abstract: The author analyzes the relation between natural law and civil law in Thomas Hobbes, pointing out Hobbes' argument that neither history or common law are able to found civil's power rationality. The article shows, as well, how sovereign power is founded by the moral law and how the equality of rights in Hobbes seems to undermine the idea that is possible for groups to be subject of rights instead individuals.

Keywords: Thomas Hobbes; Ethics; Politics; Natural law; Civil law.

\section{Sobre a lei de natureza e a lei civil}

Apesar do fato de Hobbes conceber a existência de leis naturais, a República dos homens não se encontra ordenada por regras transcendentes que constituiriam o arsenal jurídico mínimo das regras de direito. Ao contrário, a exigência de fundação de um código jurídico do Estado vem substituir uma suposta ordem natural perdida. Conhecemos a célebre e paradoxal (à primeira vista) afirmação de Hobbes segundo a qual "não é a sabedoria, mas a autoridade quem faz a lei". Essa afirmação é aparentemente paradoxal porque tal concepção de direito parece rejeitá-lo definitivamente ao domínio do puro arbítrio e abandonar ao puro poder discricionário do

\footnotetext{
* Doutor em Filosofia pela Université de Paris - I, Panthéon/Sorbonne. Professor do Programa de Pós-graduação em Direito - Unisinos.

${ }^{1}$ HOBBES, T. A dialogue between a philosopher and a student of the Common Laws of England. Chicago: University of Chicago, 1971, p. 29.
} 
soberano a tarefa de dizer a lei. Como é então possível possuir uma ciência política, isto é, uma justificação dos enunciados normativos que estabelecem a racionalidade da sociedade civil e, simultaneamente, deixar apenas ao arbítrio do soberano-legislador a tarefa de dizer a lei? Diante desse problema, Hobbes parece fazer face a uma dupla perspectiva de respostas possíveis: de um lado, certa concepção irracionalista que repousa sobre a hipótese segundo a qual as relações morais e políticas não podem ser organizadas a partir de uma ordenação racional. De outro, uma concepção ultra-racionalista que se apóia sobre a hipótese de que existe um procedimento para se estabelecer, apenas pela razão, uma ordem jurídica objetivamente válida.

Para bem situar a posição de Hobbes faz-se necessário recolocar o problema em uma dupla perspectiva: primeiramente em relação à lei natural e, em seguida, em relação à lei civil. Têm-se aqui duas abordagens que demandarão, em Hobbes, duas respostas diferentes ${ }^{2}$.

Segundo Hobbes, o desacordo entre os indivíduos racionais acerca daquilo que julgam correto fazer em circunstâncias particulares é ineliminável. Na medida em que a razão desempenha papel instrumental nas deliberações, ela não pode ser um árbitro capaz de estabelecer com imparcialidade quais interesses em conflito devem ser prioritários, uma vez que os "raciocínios corretos" das partes em conflito estão a serviço de interesses inevitavelmente parciais. A parcialidade aqui pressuposta como inevitável é o resultado da ordenação mesma das preferências individuais que constituem, cada uma, um "ponto de vista" a partir do qual as leis naturais podem ser interpretadas em circunstâncias particulares.

Isso não implica, entretanto, que a filosofia moral não possa igualmente ser "infalível e certa" - como o é, por exemplo, a aritmética -, uma vez que há aqui igualmente a possibilidade de um cálculo feito a partir de definições e termos gerais. As conclusões serão válidas, desse modo, para os tipos genéricos de ações estratégicas e suas conseqüências. Definições e termos gerais estabelecerão enunciados gerais que servirão como hipóteses de situações gerais permitindo estabelecer esquematicamente o teatro das ações humanas.

A filosofia moral e política seria, assim, estabelecida como um sistema de regras acerca do que é bom ou mau, justo ou injusto, todas as regras sendo estabelecidas com certeza, ou seja, de modo dedutivo a partir de princípios verdadeiros. Tal certeza não pode, entretanto, ser obtida no caso das ações particulares, pois não há aqui um “cálculo" realizável por um indivíduo para fazer derivar enunci-

\footnotetext{
${ }^{2}$ Sobre a relação entre lei natural e lei civil ver ZARKA, Y. C. Loi naturelle et loi civile: de la parole à l'écriture. In: Philosophie, n. 23, 1989, p. 57-79, e também ROUX, L.; TRICAUD, F. Le Pouvoir et le Droit. Hobbes et les Fondements de la Loi. Saint-Etienne: Université de Saint-Etienne, 1992.
} 
ados universais (regras gerais ou teoremas da razão) válidos para todas as circunstâncias e conseqüências particulares. Nesse sentido afirma Hobbes: "Sendo conhecidas pelos homens apenas por sua razão natural, elas [as leis naturais] não eram senão teoremas tendentes à paz, e incertos, pois que procedendo das conclusões de indivíduos particulares". 3

A diversidade de perspectivas na avaliação daquilo que pode ser considerado como bom obriga o homem a criar um soberano como garantidor da interpretação da lei natural, como o único investido do poder de instituir a lei civil. Pode-se, assim, dissolver o aparente paradoxo descrito acima. Que o roubo e o homicídio devam ser interditados em uma associação política todo ser racional convirá; todavia, determinar o que deve ser considerado como tal é outra questão. Diz Hobbes:

O roubo, o assassínio e todas as injúrias são proibidos pela lei de natureza; mas o que há de se chamar roubo, o que assassínio, adultério ou injúria a um cidadão não se determinará pela lei natural, porém pela civil. Pois roubar não é tirar de outra pessoa qualquer coisa que ela possui, mas apenas o tirar-lhe os bens; ora, o que é nosso e o que é dele compete à lei civil dizer. ${ }^{4}$

Entretanto, não obstante a diversidade de conclusões que se pode extrair de enunciados tão gerais, apesar das divergências nos juízos de valor acerca do que é agradável, útil e bom, todos os seres humanos partilham de um preceito racional comum, a saber: "Por conseguinte, todos os homens concordam que a paz é uma coisa boa, e portanto que também são bons o caminho ou meios da paz". ${ }^{5}$

Para bem situar a questão da relação entre a lei natural e a lei civil é necessário, igualmente, recordar que a figura do soberano, em Hobbes, é instituída não apenas para assegurar a paz, inviável na ausência de um poder político - isto é, na circunstância onde os homens vivam em condição natural -, mas também, e este aspecto é fundamental, para fazer valer as leis de natureza, torná-las efetivas. Há um fundamento ético indissoluvelmente ligado à instituição do poder civil, e ele se encontra no necessário conhecimento das paixões que levam os homens a agir em vista de fins particulares. A ética, também denominada de filosofia moral, estabelece, em Hobbes, os primeiros princípios da política, pois nela estão contidos "os primeiros fundamentos dos deveres ou da doutrina civil, que é o coroamento da

${ }^{3}$ HOBBES, Thomas. Of liberty and necessity: a treatise wherein all controversy concerning predestination, election, free will, grace, merits, reprobation, etc., is fully decided in answer to a tretise written by Bishop of Londonderry on the same subject, EW, IV, 284-85.

${ }^{4}$ HOBBES, Thomas. De cive, II, VI, XVI, Trad. Renato Janine Ribeiro. São Paulo, Martins Fontes, 1998, p. 112.

${ }^{5}$ HOBBES, Thomas. Leviatã, ou Matéria, Forma e Poder de um Estado Eclesiástico e Civil. 3. ed. Trad. João Paulo Monteiro e Maria Beatriz Nizza da Silva, São Paulo: Abril, 1983, p. 94. 
filosofia". ${ }^{6}$ A ciência dessas leis naturais, continua Hobbes no Leviatã , é a ética, "e a ética nada mais é do que a ciência das coisas que são boas ou más no comércio e na sociedade dos homens. [...] Desse modo, ninguém pode negar que os meios necessários à paz são bons. Ora, esses meios são a justiça, a gratidão, a modéstia, a eqüidade e todas as outras leis de natureza". ${ }^{7}$ As leis de natureza, por sua vez, são tornadas efetivas através das leis civis estabelecidas pelo poder civil. Como é sabido, para Hobbes, na ausência de um poder comum capaz de submeter os homens e fazê-los renunciar à capacidade indiscriminada de usar dos meios que julguem necessários à manutenção de sua identidade - isto é, de sua vida - com vistas à aquisição de um bem aparente futuro, as leis de natureza permanecem como simples teoremas relativos aos meios que permitem a preservação da vida humana. Pois uma lei, no sentido próprio, é a palavra daquele ou daqueles que comandam ${ }^{8}$. $\mathrm{O}$ capítulo XXVI do Leviatã define do seguinte modo essa relação entre lei natural e lei civil:

As leis de natureza e as leis civis contêm-se mutuamente. Toda lei de natureza, com efeito, é uma virtude moral: assim são a equidade, a justiça e a gratidão, que, como foi dito ao final do capítulo XV, não são leis propriamente ditas, mas qualidades. Elas são realmente leis, mas leis civis, quando a cidade comanda observá-las. As leis naturais são, portanto, também, leis civis. ${ }^{9}$

Ora, uma vez que o poder soberano foi instituído para dar efetividade às leis naturais, é a elas, portanto, que se deve voltar o legislador, como razão ou fundamento, no momento de criação das leis civis. A lei civil, por sua vez, enquanto comando, deve ser notificada, por oral, por escrito ou por outro sinal apropriado, àqueles a quem se destina. Além disso, ela deve ser interpretada. Assim, prossegue Hobbes:

Uma vez conhecidas as leis e o legislador, resta ainda, se as leis devem ser obrigatórias, compreender sua verdadeira interpretação, na qual apenas consiste a essência da lei. Ora, pertence à mesma pessoa comandar e interpretar seus comandos, ordenar e explicar suas ordens. O único intérprete de todas as leis é, pois, o detentor do poder soberano ou aquele a quem foi dada autoridade nessa matéria. ${ }^{10}$

\footnotetext{
${ }^{6}$ HOBBES, Thomas. De Corpore, Elementorum philosophiae sectio prima. OL, I, VI, 17, 77-78; EW, 87.

${ }^{7}$ HOBBES, Thomas. Leviatã latino. OL. Trad. e anot. por François Tricaud e Martine Pécharman. Paris : Vrin, 2004, cap. XV, p. 129-130.

${ }^{8}$ Cf. HOBBES, Thomas. Leviatã latino. OL., cap. XV, p. 130.

${ }^{9}$ Idem ibidem, cap. XXVI, p. 206.
} 
A prerrogativa reivindicada pelo poder soberano de ser o único intérprete autorizado da lei civil é a condição mesma da paz. Evidentemente, todo cidadão pode interpretar a lei civil. Apenas a cidade pode interpretá-la definitivamente. "Uma vez a cidade (poder civil) instituída, a interpretação das leis naturais não depende dos doutores e dos escritores de filosofia moral, mas da autoridade da cidade (civil). Suas doutrinas podem ser verdadeiras, mas é a autoridade, e não a verdade, que faz a lei". ${ }^{11}$

Permanece ainda o problema relativo à interpretação da lei, pois será de tal interpretação que dependerá a potência da República. Um soberano que não busca em um litígio, por exemplo, tratar igualmente as partes, enfraquece sua potência, pois, ao cometer um ato hostil contra um ou alguns cidadãos, contraria a própria finalidade pública de sua instituição. A continuidade do poder político depende, pois, do respeito às leis de natureza, inscritas na cidade pela lei civil, e da efetivação do princípio mesmo da soberania, a salus populi. Da lei civil depende, portanto, a paz. Ora, continua Hobbes:

[...] toda lei escrita, que seja composta de muitas ou poucas palavras, apenas pode ser compreendida a partir das causas finais da lei ela mesma: ora, o conhecimento dessas causas pertence ao legislador apenas. Apenas ele pode resolver as dificuldades e os nós das leis, desatando-os ou resolvendo-os. ${ }^{12}$

Para Hobbes, a eqüidade e as leis constituem a razão e a vontade artificial da República. A unidade da cidade (civitas) reside na composição de todos os seus membros em torno de sua finalidade. Os magistrados, legisladores, conselheiros etc. agem enquanto prepostos dessa vontade artificial da qual se investe o poder soberano. Tem-se aqui uma distinção fundamental entre a pessoa moral e a pessoa natural do soberano. Essa distinção é crucial, uma vez que se deve bem compreender que o princípio da soberania não repousa na vontade natural do soberano, mas na vontade que é a sua enquanto pessoa moral - isto é, enquanto representante da República.

Portanto, quando os magistrados se interrogam, por exemplo, acerca da significação de expressões como "processo legal regular" ou "igual proteção das leis",

\footnotetext{
${ }^{10}$ HOBBES, T. Leviatã latino. Opera latina, III, 209.

${ }^{11}$ HOBBES, T. Leviatã latino. Opera latina, III, 202: "In civitate constituta, legum naturae interpretatio non a doctoribus et scriptoribus moralis philosophiae dependent, sed ab authoritate civitatis. Doctrinae quidem verae esse possunt; sed authoritas, non veritas, facit legem".

${ }^{12}$ HOBBES, Thomas. Leviatã latino, OL., cap. XXVI, p. 210-11. Estas três últimas citações buscam chamar a atenção sobre a necessidade de que a lei seja notificada e interpretada. Na obscuridade da lei é preciso buscar sua causa final.
} 
presentes em inúmeras Constituições contemporâneas, é a vontade pública do poder civil, segundo Hobbes, que eles deveriam interrogar. É preciso compreender que, em Hobbes, a interpretação da lei não é nem uma introspecção psicológica acerca daquilo que pensa o poder político, nem uma prospecção histórica, mas uma atividade estritamente jurídica e política.

Para responder sobre a significação da lei faz-se necessário dirigir-se ao legislador. Mas quem é o legislador? Ele é, como explicado acima, o soberano. Mas, finalmente, quem é o soberano e qual é a sua vontade? Vejamos o que Hobbes tem a dizer sobre isso:

A interpretação correta de não importa qual lei natural [e, acrescentaria aqui, de toda lei] é a sentença do detentor do poder supremo ou daquele a quem ele deu autoridade para conhecer tais causas. Esse último dá sua interpretação aplicando a lei ao fato. E essa interpretação é autêntica não porque é a sua sentença, mas porque é a da cidade. ${ }^{13}$

A interpretação, portanto, é autêntica porque é dada pelo soberano em sua pessoa pública, isto é, enquanto representante da cidade. A intenção que é preciso buscar é, pois, a da civitas. Se lembrarmos agora que o soberano é instituído para fazer valer as leis de natureza, todo problema consistirá em saber qual decisão é a melhor para a conservação da República, para a preservação da paz civil. Nesse ponto é necessário citar outra passagem de Hobbes, que descreve o funcionamento da razão do juiz: "Assim, se ele [o soberano] institui um juiz, é preciso que esse preste atenção ao fato de que sua sentença deve estar de acordo com a razão de seu soberano: e essa, sendo sempre suposta coincidir com a eqüidade, ele está a ela limitado pela lei de natureza". ${ }^{14}$

A eqüidade de que nos fala Hobbes consiste, para alguém que decide um conflito, em tratar as partes com igualdade. Sem isso destroem-se as arbitragens, os julgamentos e, conseqüentemente, a paz ela mesma. A eqüidade, nesse contexto, implica a imparcialidade no tratamento das partes em litígio. A eqüidade exige, pois, tratar a todos igualmente. Segundo ela, os juízes devem aplicar as leis igualmente a todos os cidadãos.

Assim, princípios jurídicos excessivamente genéricos exigirão, para sua interpretação, um recurso, segundo Hobbes, às leis naturais enquanto apontando o fim a que se destinam todas as leis civis. Uma formulação tão ampla exige que o juiz decida em função de certo fim que a norma aponta.

${ }^{13}$ HOBBES, Thomas. Léviatã latino, OL., cap. XXVI, p. 210. Grifo nosso.

${ }^{14}$ HOBBES, Thomas. Leviatã, éd. MacPherson, Harmondsworth: Penguin Books, 1968, p. 318. 


\section{A crítica à tradição e ao modelo jurídico do common law enquanto fundamento da lei civil}

Não é, segundo Hobbes, na intenção do legislador histórico que se deve buscar o sentido da lei. A renúncia ao uso do direito natural e a correspondente outorga à pessoa civil do soberano do direito de distinguir entre o certo e o errado não repousa em um momento mítico ancestral de renúncia recíproca de todos ao uso do direito natural. O poder soberano se exerce no tempo presente, e é nesse tempo que a intenção da vontade pública deve ser perscrutada. A interpretação da lei civil é uma prerrogativa do poder soberano que se exerce sempre no tempo presente:

Com efeito, o legislador não é aquele pela autoridade de quem as leis foram instituídas no começo, mas aquele pela autoridade de quem elas são mantidas. [...] essas leis, mesmo se elas são muito antigas, tiram sua força de lei não do costume, mas da vontade do poder supremo do momento. ${ }^{15}$

Os argumentos históricos, ao contrário, não se apóiam, em definitivo, na ordem jurídica positiva. Eles tomam como apoio algo que está para além do texto: uma história, uma ancestralidade, um momento fundador e petrificador da interpretação.

Uma coisa é certa: a atividade do juiz não é oracular - isto é, ela não consiste em propor uma interpretação arbitrária da lei. Além disso, se a ancestralidade constituísse a autoridade poderíamos, segundo Hobbes, produzir mil autoridades que se contradiriam umas às outras. A história, a razão privada e mesmo a arte do juiz são impotentes para estabelecer o sentido da lei. Para Hobbes, a história nada pode ensinar acerca dos fundamentos do direito, da justiça e da soberania.

Os precedentes, por exemplo, podem ser revistos, pois gerações futuras podem compreender que interpretações pensadas outrora como necessárias e mesmo apropriadas servem, de fato, apenas para oprimir ${ }^{16}$.

Quanto à intenção originária dos primeiros legisladores, também ela não encontra fundamento na República. Com efeito, reencontrar a intenção do legislador é algo bem diferente de interpretar o texto que é o produto da atividade legislativa. Quando Hobbes afirma que é preciso buscar o fim da lei e que esse consiste na vontade do soberano, não se deve compreender aqui, como ficou demonstrado, que é de sua vontade enquanto pessoa privada de que se trata. A vontade do soberano

${ }^{15}$ HOBBES, Thomas. Leviatã latino, OL., cap. XXVI, p. 207. "Legum earum authoritas, etsi antiquissimae sint, vim Legum, non à Consuetudine, sed à voluntate Summae Potestatis praesentis habent".

${ }^{16}$ Cf. HOBBES, Thomas. Leviatã latino, OL., cap. XXVI, p. 210. 
é a vontade pública, a qual é preciso sempre interpretar em função de uma situação presente. Dito de outro modo, não se trata de procurar compreender a intenção do legislador à época em que o texto foi promulgado, mas, antes, o texto ele mesmo no contexto presente.

\subsection{A crítica à razão artificial}

Os séculos XVI e XVII foram na Europa um período de colisão entre a autoridade dos reis e os privilégios locais ou nacionais, liberdades e constituições. Neste período, a common law compreendia, além das leis (statutes), as proclamações reais, decisões judiciais antigas e muitas leis que se acreditava não-escritas.

A busca do costume como fonte primordial da experiência jurídica procura afirmar o caráter imemorial do direito que se quer justificar. Ele pertence a uma história particular, a um povo particular ${ }^{17}$. Para isto, portanto, é preciso identificar a singularidade da constituição de um direito antigo, imemorial e nacional ${ }^{18}$. Fazia-se necessário, portanto, construir um passado, uma história e um direito. Hotman, em Francogallia, afirmou a antiguidade da assembléia da nação; Coke, na Inglaterra, a do parlamento e do Common Law; Pietro de Gregorio, na Sicília, a antigüidade dos privilégios baroniais e do parlamento; François Vranck, nos Países-Baixos, a da soberania e independência das cidades holandesas; Erik Sparre, na Suécia, a dos nobres em seus riksrad ${ }^{19}$. Em seu livro Antitribonianus, composto em 1567, Hotman dividia seus ataques à tradição jurídica em duas áreas: primeiro, era preciso desacreditar a suposta relevância do direito romano; em segundo lugar, minar sua aparente perfeição ${ }^{20}$.

A grande questão, nesse período, consistia, portanto, em posicionar-se entre a necessidade de proceder a uma síntese dos costumes regionais e estabelecer a sua

\footnotetext{
${ }^{17}$ Temos aqui um dos leitmotif dos ataques proferidos pelos humanistas à tradição jurídica medieval. Para um estudo da reforma humanista do método e o surgimento de uma perspectiva crítica em relação ao passado e ao direito romano em particular, ver FRANKLIN, J. H. Jean Bodin and the sixteenthcentury revolution in the methodology of law and history. New York: Columbia University, 1963.

${ }^{18}$ Para Jean Bodin, jurista e estudioso da história comparada, o domínio de um adequado conhecimento crítico da história deveria vir acompanhado de um treinamento na arte jurídica, pois é a partir do direito e dos costumes de um povo que as reais fundações de um Estado são conhecidas. Cf. BODIN, J. Methodus ad facilem historiarum cognitionem. In: Euvres, t. 1, Mesnard, Pierre (ed.). Paris: PUF, 1951, p. 125 A.

${ }^{19}$ Cf. POCOCK, J. G. A. The Ancient Constitution and the Feudal Law. Cambridge University, 1957.

${ }^{20}$ Cf. HOTMAN, François.Antitribonianus sive dissertatio de studio legum, in Variorum opuscula ad cultiorem jurisprudentiam adsequendam pertinentia, v. VII, Pisa, 1771, cap. III, p. 20-21.
} 
concórdia com o direito público em geral ou, ao contrário, redigir um costume nacional onde todos os antigos costumes se fundariam.

É neste contexto que emerge a crítica hobbesiana ao modelo jurídico do common law, sustentado por todos aqueles que, como Sir Edward Coke, propunham atribuir juridicidade a uma regra em virtude de representar o costume imemorial (immemorial custom) de um povo. Em seus livros Leviathan, A dialogue between a philosopher and a student of the Common Laws of England e Behemoth, or the Long Parliament ${ }^{21}$, Hobbes ataca tal concepção de direito fundada na idéia da existência de uma prática jurídica remota que constituiria uma espécie de "razão artificial", isto é, uma sabedoria acumulada ao longo de gerações e à qual acederiam apenas aqueles estudiosos conhecedores da história de um povo. Hobbes não pode aceitar tal limitação histórica do direito. A lei pode, é certo, ser um costume, mas este, por ele mesmo, não possui força vinculante. Para que um costume seja lei é necessário que exista já uma autoridade capaz de produzir, por seus comandos, um preceito jurídico. Deste modo, para o filósofo de Malmesbury, a idéia mesma de um direito imemorial é desprovida de qualquer justificativa racional. Para que exista direito é necessário haver soberano.

No início do Dialogue, o filósofo solicita ao estudioso do common law que explique como Coke, falando pelos juristas, pode evitar a censura de que, ao subordinar o direito à razão, estaria destruindo a lei através do encorajamento da desobediência. O estudioso do common law (lawyer), por sua vez, cita o dictum de Coke segundo o qual o direito não está baseado naquilo que é razoável à luz de um homem qualquer enquanto razoável, mas apenas no acordo com a razão dos homens que possuem a arte jurídica. $O$ filósofo, então, responde não haver uma arte cuja posse habilite um homem ou homens a fazer a lei: "Não é a sabedoria, mas a autoridade que faz a lei". ${ }^{22}$

Poderíamos aqui perguntar : que sabedoria é esta ? O propósito de Hobbes é precisamente tornar claro que não há tal coisa como um common law que foi gerado pela destreza ou experiência de qualquer corpo de homens essencialmente desautorizados - tal como ele considera ser o caso de juristas e juízes. A impostura, ao menos com referência ao estudioso do common law, como mostrará o Dialogue, procede do fato de que ele, reivindicando traduzir a razão em direito, deve necessariamente falhar, pois não possui razão, mas um falso fac-símile dela - isto é, a arte.

${ }^{21}$ HOBBES, T. A dialogue between a philosopher and a student of the Common Laws of England. ed. Cropsey. Chicago: University of Chicago, 1971. Como anuncia o título, o livro é escrito sob a forma de diálogo entre um estudioso do common law

(lawyer) e o filósofo.

${ }^{22}$ Ibidem, p. 29: "It is not wisdom, but authority that makes a law". 
Definitivamente, não constitui uma tarefa oracular a atividade de estabelecer a lei. Ademais, se a antigüidade pode servir de autoridade, podemos sucessivamente produzir mil autoridades que se contradizem umas às outras. A história, a razão privada, a erudição e a posse da arte jurídica, como foi dito, não traduzem o direito.

Para Hobbes, a história nada tem a ensinar acerca dos fundamentos do direito, da justiça ou da soberania ${ }^{23}$. Aos seus olhos, todo poder encontra-se historicamente fundado sobre algum ato de violência. Deste modo, nenhuma justificação racional pode ser extraída de tais eventos para justificar a obediência ao soberano. Ao final do Leviatã, Hobbes volta a afirmar:

Cada qual quer justificar a guerra pela qual seu poder foi, na origem, obtido, e da qual, pensam (e não da posse) depende seu direito: como se, por exemplo, o direito dos reis da Inglaterra dependesse do valor da causa de Guilherme o Conquistador e do fato de que eles descendem dele em linha reta. Nesta perspectiva não haveria talvez hoje, no mundo inteiro, nenhum laço de obediência do súdito com o soberano. [...] Conseqüentemente, coloco no âmbito dos germes os mais certos da morte de todo Estado a pretensão dos conquistadores de obter não apenas a soberania das ações futuras dos homens, mas também a aprovação de todas as ações passadas, enquanto que não existem absolutamente repúblicas no mundo cujos inícios possam conscientemente ser justificados. ${ }^{24}$

Sem dúvida, o que conduziu grande parte dos comentadores a considerar Hobbes como o fundador de uma concepção absolutista, mesmo totalitária de fundação do Estado, foi o fato de tomar os argumentos acima expostos como constituindo as premissas das quais parte seu raciocínio, negligenciando-se o fato de que, na verdade, trata-se de conclusões às quais Hobbes chega após uma longa reflexão acerca do mundo e da natureza humana ${ }^{25}$.

Todavia, ainda que a atribuição a Hobbes desta idéia geral de uma soberania absoluta, juntamente com todas as conseqüências que daí decorrem, não seja falsa

\footnotetext{
${ }^{23}$ Hobbes nega que a história ou a religião permita estabelecer que a monarquia, por exemplo, é a melhor forma de governo, "pois eles [os argumentos] procedem a partir de exemplos e testemunhos e não por razões". De Cive, X, 3 .

${ }^{24}$ HOBBES, T. Leviatã. Revisão e conclusão, p. 716.

${ }^{25} \mathrm{O}$ projeto de Hobbes, reafirmado em diversas partes de sua obra, foi sempre o de construir um sistema filosófico unificado na trilogia De Corpore, De Homine e De Cive--, constituído a partir de uma dedução contínua dos argumentos. Para uma posição contrária a esta perspectiva, ver sobretudo: TAYLOR, A., E. The ethical doctrine of Hobbes Philosophy, XIII, n. 52, 1938, p. 406-24. WARRENDER, H. The Political philosophy of Hobbes. Oxford: Clarendon, 1957. Para uma exposição dessa centrovérsia, ver: LISBOA, W. B. Algumas questões acerca dos fundamentos da filosofia civil em Thomas Hobbes. Estudos Jurídicos (Unisinos), São Leopoldo, v. 38, n. 3, p. 65-68, 2005.
} 
(direito absoluto de propriedade, monopólio na produção do direito e do uso da força), ela induz a erro ao suprimir ou desconsiderar outra dimensão fundamental para Hobbes na constituição do estado civil, a saber: as condições morais de constituição do poder soberano que o torna um estado durável de relações civilizadas entre os homens. Assim, se por um lado Hobbes insiste no Leviatã sobre as dimensões políticas do estado civil, por outro ele consagra dois capítulos inteiros desta obra (capítulos XIV e XV) à especificação e detalhamento das condições morais de um tal Estado, as quais ele denomina, seguindo nisto a tradição dos teóricos do direito natural, de leis de natureza.

A natureza, para o filósofo de Malmesbury, não contém seres cuja finalidade reside na realização acabada de sua essência. Ao contrário, a natureza produz apenas indivíduos que têm como fim único a conservação de seu movimento - o que significa, para o caso dos indivíduos vitais, a conservação da própria vida ${ }^{26}$. Estes indivíduos, por ter um mesmo princípio de individuação, são estritamente iguais de fato e de direito.

No parágrafo XIII, capítulo III, do De Cive, Hobbes atribui a tese da desigualdade natural entre os homens àquele a quem considera seu verdadeiro protagonista:

Sei que Aristóteles, no primeiro livro de sua Política, afirma - como um dos primeiros fundamentos da ciência política - que alguns são feitos, por natureza, dignos de mandar, outros apenas para servir: como se senhor e servo se distinguissem não apenas pelo consentimento dos homens, mas por uma aptidão, ou seja, por uma espécie de conhecimento ou ignorância naturais.

Ora, tal fundamento não é desmentido somente pela razão [...], mas também o é pela experiência. ${ }^{27}$

Para Hobbes, não existe nenhuma desigualdade natural objetiva entre os homens capaz de fornecer um fundamento à desigualdade de direitos. A condição natural dos homens, no que concerne à felicidade e à vida presente ${ }^{28}$, pode ser comprovada em uma dupla perspectiva: quanto às capacidades corporais e quanto às intelectuais. Quanto às primeiras, a despeito da existência de diferenças individuais, é forçoso acordar que os homens são iguais quanto à capacidade de se destruir mutuamente: "Porque quanto à força corporal o mais fraco tem força suficiente

\footnotetext{
${ }^{26}$ HOBBES, T. Leviatã, op. cit., cap. VI.

${ }^{27}$ HOBBES, T. Do Cidadão. Trad., apres. e notas por Renato Janine Ribeiro. São Paulo: Martins Fonte, 1998, p.62.

${ }^{28}$ Título do Leviatã latino, que difere do Leviatã inglês: "Of the natural condition of mankind as concerning their felicity, and misery".
} 
para matar o mais forte, quer por secreta maquinação, quer aliando-se com outros que se encontrem ameaçados pelo mesmo perigo"29. Quanto às segundas, Hobbes aí encontra uma igualdade ainda maior entre os homens:

Pois a natureza dos homens é tal que, embora sejam capazes de reconhecer em muitos outros maior inteligência, maior eloqüência ou maior saber, dificilmente acreditam que haja muitos tão sábios como eles próprios [...]. Mas isto prova que os homens são iguais quanto a esse ponto, e não que sejam desiguais. Pois geralmente não há sinal mais claro de uma distribuição eqüitativa de alguma coisa do que o fato de todos estarem contentes com a parte que lhes coube. ${ }^{30}$

Desta igualdade natural, portanto, é impossível deduzir um direito natural de comandar ou um dever natural de obedecer. Não existe nenhuma desigualdade natural objetiva entre os homens capaz de fornecer fundamento à dedução de uma desigualdade de direitos. Da igualdade quanto à capacidade deriva, segundo Hobbes, a igualdade quanto à esperança de atingir-se os fins buscados. Assim, se dois homens desejam a mesma coisa, ao mesmo tempo em que é impossível que ela seja gozada por ambos, eles tornam-se inimigos. Todos entrarão, então, em competição para obter e acumular poder, o que conduz ao estado de guerra ${ }^{31}$.

Para ultrapassar este conflito é necessário, segundo Hobbes, empreender todos os esforços para obter a paz. Tal é mesmo o conteúdo da primeira lei de natureza: "Que todo homem deve esforçar-se pela paz, na medida em que tenha esperança de consegui-la, e caso não a consiga pode procurar e usar todas as ajudas e vantagens da guerra". ${ }^{32}$ A segunda lei, que se desimplica da primeira, estabelece o procedimento para alcançar a paz: é necessário que cada um concorde em renunciar a seu direito sobre todas as coisas (isto é, a usar de todos os meios que julgue necessários à manutenção de sua vida) se, e somente se, existir uma reciprocidade coletiva em tal renúncia ${ }^{33}$. Assim, para Hobbes, o direito dos demais indivíduos não é a contrapartida de nossas obrigações em relação a eles. Ao contrário, a segunda

${ }^{29}$ HOBBES, T. Leviatã, cap. XIII, p. 75.

${ }^{30}$ HOBBES, T. Leviatã, cap. XIII, p. 75.

${ }^{31} \mathrm{O}$ argumento hobbesiano acerca da condição natural de guerra entre os homens é, na verdade, muitíssimo mais sofisticado. Para um estudo detalhado desta temática, ver ZARKA, Y. C. La décision méthaphysique de Hobbes. Condition de la Politique. Paris : Vrin, 1987.

${ }^{32}$ HOBBES, T. Leviatã, XIV, p. 78.

${ }^{33}$ Esta segunda lei afirma: “Que um homem concorde, quando outros também o façam, e na medida em que tal considere necessário para a paz e para a defesa de si mesmo, em renunciar a seu direito a todas as coisas, contentando-se, em relação aos outros homens, com a mesma liberdade que aos outros homens permite em relação a si mesmo". Leviatã, XIV, p. 79. Renunciar ao direito sobre todas as coisas não significa, em Hobbes, renunciar a todo direito. Cada indivíduo conserva o direito de poder se defender em caso de agressão, ao mesmo tempo em que reconhece semelhante direito aos demais. 
lei de natureza prescreve que cada indivíduo, em seu fórum interno, deve buscar, para sua preservação, uma autolimitação de seu próprio direito. Tal dedução da igualdade de direito entre os homens em sua condição natural funda-se, portanto, sobre a igualdade natural de fato ${ }^{34}$.

Pode-se, assim, concluir que a natureza não produz, nem de fato nem de direito, qualquer hierarquia entre os homens, seja no que concerne a sua conservação, seja no que diz respeito ao exercício do poder entre os indivíduos uns sobre os outros. Se uma hierarquia existe, ela se encontra fundada em um consentimento, expresso ou tácito, daqueles que são governados. Tal consentimento, por sua vez, exprime-se sob a forma de um pacto. Se tal não é o caso, ao poder de fato não corresponderá uma obrigação de obediência.

Pela mesma razão os indivíduos não podem reclamar o mérito natural. Nenhum homem é mais digno que outro, a menos que a própria lei civil estabeleça entre eles certa desigualdade. Hobbes, portanto, irá desqualificar a idéia de uma justiça distributiva fundada em um justo natural ${ }^{35}$.

Em Hobbes, destarte, o mérito não cria nenhum direito, nem objetivo nem subjetivo, e, se ele é retribuído, não é em virtude de uma obrigação, mas por uma graça. A justiça comutativa torna-se justiça dos contratantes e diz respeito à execução dos contratos, enquanto que a justiça distributiva designa apenas a função de arbitragem do juiz ${ }^{36}$.

Se Hobbes está correto na sua crítica da história e da razão artificial enquanto impotentes para profetizar as leis civis, então uma série de conseqüências pode ser extraída para uma análise do debate jurídico contemporâneo.

\section{O que o século XVII tem a nos ensinar}

A tradução para um vocabulário contemporâneo destes argumentos historicamente datados coloca em evidência o ponto visado por uma determinada maneira de argumentar. Recolocada a problemática moderna para os dias atuais, poderíamos legitimamente perguntar se a idéia de direitos específicos de uma minoria ou de grupos culturais não reintroduziria privilégios contrários à igualdade de direitos que é constitutiva de uma sociedade democrática. Se os direitos culturais são direitos coletivos, então eles serão vinculados a dispositivos de constrangimento dos demais membros da comunidade. Mas quem será então o sujeito de direitos coletivos? Se

\footnotetext{
${ }^{34}$ A nona lei natural igualmente determina "que cada homem reconheça os outros como seus iguais por natureza. A falta deste preceito chama-se orgulho“. Leviatã, XV, p. 92.

${ }^{35}$ Cf. HOBBES, T. De Cive, III, 6.

${ }^{36}$ Cf. HOBBES, T. Leviatã, XV, p. 90.
} 
tais direitos, ao que parece, são da coletividade, então indivíduos apenas poderão exercê-lo na medida em que pertencerem ao grupo em questão. Vejamos, neste ponto, a opinião de Charles Taylor:

Com a política da igual dignidade, o que é estabelecido é suposto ser universalmente o mesmo, um conjunto idêntico de direitos e de privilégios. Com a política da diferença, o que nos é pedido reconhecer é a identidade única deste indivíduo ou deste grupo, o que o distingue de todos os outros. A idéia é que é precisamente esta distinção que foi ignorada, silenciada, assimilada a uma identidade dominante ou majoritária. ${ }^{37}$

O que a representação diferenciada de um grupo ou minoria e a cidadania multicultural parecem traduzir é uma pura e simples decomposição do político e um abandono da sociedade civil aos conflitos de interesses antagônicos de diferentes comunidades. Quais serão, por exemplo, os direitos de minorias étnicas e culturais que, buscando afirmar o direito à diferença, recusam a autonomia da pessoa, buscando, ao contrário, afirmar sua legitimidade em constranger, no âmbito dos seus, ao casamento forçado, à inferioridade da mulher em relação ao homem, à desigualdade na distribuição dos quinhões hereditários, ao repúdio, à lapidação e à infibulação?

Talvez um dos legados mais vigorosos da teoria do direito natural moderno, prolongada nas noções de direitos do homem e de dignidade humana no século XVIII, seja a idéia de que os regimes representativos devem combater duas formas complementares de tirania: a de uma maioria e, por extensão, a de uma minoria (ou de muitas). Enfim, qual o limite da tolerância?

\section{Referências}

BODIN, J. Methodus ad facilem historiarum cognitionem. In: Cuvres, t.1. MESNARD, Pierre (ed.). Paris: PUF, 1951.

FRANKLIN, J. H. Jean Bodin and the sixteenth-century revolution in the methodology of law and history. New York: Columbia University, 1963. HOBBES, Thomas. De cive. Trad. Renato Janine Ribeiro. São Paulo: Martins Fontes, 1998.

. De Corpore. Elementorum philosophiae sectio prima. Édition critique, notes, appendices et index par K. Schuhmann. Paris: Vrin, 1999.

${ }^{37}$ TAYLOR, C. Multiculturalisme. Différence et démocratie. Paris: Aubier, 1994, p. 57. 
. Leviatã, ou matéria, forma e poder de um estado eclesiástico e civil. 3. ed. Trad. João Paulo Monteiro e Maria Beatriz Nizza da Silva. São Paulo: Abril, 1983.

. A dialogue between a philosopher and a student of the Common Laws of England. ed. Cropsey. Chicago: University of Chicago, 1971.

. Leviathan. ed. MacPherson. Harmondsworth: Penguin Books, 1968. . Léviathan latino, OL. Trad. e anot. por François Tricaud e Martine Pécharman. Paris: Vrin, 2004.

. Of liberty and necessity: a treatise wherein all controversy concerning predestination, election, free will, grace, merits, reprobation, etc., is fully decided in answer to a tretise written by Bishop of Londonderry on the same subject. English Works, ed. W. Molesworth, Londres, 1839-1845, reproduzido por Scientia Verlag, Aalen, 1966, e Routledge-Thoemmes Press, 11 t. em 12 vol., Londres, 1992.

HOTMAN, François. Antitribonianus sive dissertatio de studio legum, in Variorum opuscula ad cultiorem jurisprudentiam adsequendam pertinentia, v. VII, Pisa, 1771.

LISBOA, W. B. Algumas questões acerca dos fundamentos da filosofia civil em Thomas Hobbes. Estudos Jurídicos (Unisinos), São Leopoldo, v. 38, n. 3, 2005. POCOCK, J. G. A. The Ancient Constitution and the Feudal Law. Cambridge University, 1957.

ROUX, L.; \& TRICAUD, F. Le Pouvoir et le Droit. Hobbes et les Fondements de la Loi. Saint-Etienne : Université de Saint-Etienne, 1992.

TAYLOR, A. E. The ethical doctrine of Hobbes. Philosophy, XIII, n. 52, 1938.

TAYLOR, C. Multiculturalisme. Différence et démocratie. Paris: Aubier, 1994, p. 57.

WARRENDER, H. The political philosophy of Hobbes. Oxford: Clarendon, 1957.

ZARKA, Y. C. Loi naturelle et loi civile: de la parole à l'écriture. In:

Philosophie, n. 23, 1989, p. 57-79.

. La décision méthaphysique de Hobbes. Condition de la Politique.

Paris: Vrin, 1987. 